\title{
Molecular Analysis of Bacterial Cytolysins
}

\author{
Trinad Chakraborty, Sophia Kathariou, Jörg Hacker, \\ Herbert Hof, Burkhard Huhle, Wilma Wagner, \\ Michael Kuhn, and Werner Goebel
}

Institut für Genetik und Mikrobiologie der Universität Würzburg, Würzburg, Federal Republic of Germany

\begin{abstract}
Results of molecular and pathogenic studies of three different bacterial hemolysins (cytolysins) are presented. These exoproteins derive from the two gram-negative bacteria Escherichia coli and Aeromonas hydrophila and from the gram-positive pathogen Listeria monocytogenes. The hemolysin of $E$. coli is determined by an 8-kilobase $(\mathrm{kb})$ region that includes four clustered genes $(h l y C, h l y A, h l y B$, and $h l y D)$. This hemolysin determinant is part either of large transmissible plasmids or of the chromosome. The genes located chromosomally are found predominantly in $E$. coli strains that can cause pyelonephritis and/or other extraintestinal infections. A detailed analysis of the chromosomal $h l y$ determinants of one nephropathogenic $E$. coli strain revealed the existence of specific, large chromosomal insertions $75 \mathrm{~kb}$ and $100 \mathrm{~kb}$ in size that carry the hly genes but that also influence the expression of other virulence properties, i.e., adhesion and serum resistance. The direct involvement of $E$. coli hemolysin in virulence could be demonstrated in several model systems. The genetic determinants for hemolysin (cytolysin) formation in A. hydrophila (aerolysin) and $L$. monocytogenes (listeriolysin) are less complex. Both cytolysins seem to be encoded by single genes, although two loci (aerB and $\operatorname{aer} C$ ) that affect the expression and activity of aerolysin have been identified distal and proximal to the structural gene for aerolysin $(a e r A)$. Cytolysin-negative mutants of both bacteria were obtained by site-specific deletion and/or transposon mutagenesis. These mutants show a drastic reduction in the virulence of the respective bacteria.
\end{abstract}

Synthesis of hemolysins has been reported throughout a broad spectrum of gram-negative and grampositive bacterial species. The in vivo action of hemolysins ultimately causes physical damage to a variety of eukaryotic cells. Bacterial products possessing such a membrane-damaging action have been termed cytolysins, and a cytolytic action on eukaryotic cells has been demonstrated for many of the hemolysins. The biochemical basis of hemolysis (cytolysis) varies and may either be enzymatic (e.g., the phospholipase of Pseudomonas aeruginosa) or nonenzymatic (e.g., the thiol-activated cytolysins of several gram-positive bacteria).

The introduction of genetic techniques, especially recombinant-DNA techniques, has accelerated detailed studies of hemolysin synthesis and transport in a number of bacteria. The isolation of the genes and their gene products, in conjunction with the study of animal models, has helped to elucidate the contribution of hemolysin to the virulence of hemolytic strains. The most extensive studies of hemolysins have been performed in Escherichia coli,

Please address requests for reprints to Dr. W. Goebel, Institut für Genetik und Mikrobiologie der Universität Würzburg, Röntgenring 11, 8700 Würzburg, Federal Republic of Germany. but progress has also been made recently in the genetic analysis of other hemolysins from both grampositive and gram-negative bacteria. Although more hemolytic extracellular proteins have been described and characterized in gram-positive than in gramnegative bacteria, less work has been reported on the genetics of these hemolysins. This lack reflects the difficulties encountered in cloning hemolysin genes from gram-positive bacteria. Cloning of such genes in $E$. coli is often accompanied by problems of limited transport, possibly incorrect processing of putative precursors, and, at times, of imperfect gene expression. Here we describe molecular studies on the hemolysins (cytolysins) of three bacterial systems: E. coli, Aeromonas hydrophila, and Listeria monocytogenes. It is further shown that these cytolysins represent important virulence factors.

\section{Results and Discussion}

\section{Hemolysin from Escherichia coli}

The genetics of $\alpha$-hemolysin synthesis in $E$. coli was intensively studied during the past years (for review see $[1,2])$. Hemolysin synthesis is observed mainly in $E$. coli strains that cause extraintestinal infections, 
and the incidence of hemolytic strains is particularly high in $E$. coli strains that cause pyelonephritis. These strains carry the hly determinant predominantly on the chromosome, whereas many hemolytic $E$. coli isolates from animal sources harbor plasmidencoded $h l y$ determinants. The chromosomal and the extrachromosomal hly determinants are highly homologous and consist of four structural genes, designated as $h l y C, h l y A, h l y B$, and $h l y D$ [3]. These four hly genes are controlled by at least two promoters. One promoter $\left(p h l y_{L}\right)$ is located proximal to $h l y C$. Transcription of $h l y C, h l y A$, and possibly $h l y B$ starts from this promoter. A sequence of more than 400 base pairs (bp) proximal to $h l y C$ has been shown to be necessary for full promoter activity in a chromosomal hly determinant [4]. The corresponding promoter sequence of most extrachromosomal hly determinants differs considerably in its nucleotide composition from the chromosomal sequence $[5,6]$ and seems to be interrupted by an IS2 insertion at position -470 bp proximal to $h l y C$ (position 1 being the first nucleotide of the hlyC gene) since a sequence proximal to IS2 that acts in the cis position is necessary for the full expression of the plasmid-encoded hly genes. At least three different phly sequences have so far been identified in seven $h l y$ determinants analyzed [6]. A second promoter initiates the transcription of $h l y D$.

The precise location of this promoter is not yet known. The plasmid-encoded $h l y$ determinant is flanked in most Hly plasmids by insertion-type elements, whereas chromosomal hly determinants may be located on larger chromosomal inserts (70-100 $\mathrm{kb}$ ) that carry short, directly repeated sequences at their ends [7]. Homologous recombination between the two direct repeats leads to deletions that remove these inserts precisely. The nephropathogenic $E$. coli O6 strain 536 carries two such inserts of $75 \mathrm{~kb}$ and $100 \mathrm{~kb}$ in size, both of which contain an active hly determinant ( $h l y I$ and $h l y I I$ ). Two types of spontaneous deletion mutants, which suffered deletions of either one ( $h l y I$ or $h l y I)$ or both inserts ( $h l y I$ and $h l y I I)$, were obtained from this strain. The latter mutant type (type I) lacks not only the hemolytic phenotype but also the expression of the mannose-resistant hemagglutination that is associated with both S-type fimbriae ( $s f a$ ) [8] and a drastic decrease in serum resistance [9]. By analyzing type II mutants (hlyI or hlyII), it can be shown that serum resistance is associated with the hlyII-carrying insert. The block expression and the expression of the $s f a$ genes of the hemolytic phenotype occur at the transcriptional level [7].

Type I mutants are nonvirulent when tested in several animal models [10] and thus can be used as suitable hosts for reconstitution of virulence by reintroduction of cloned virulence genes. Hemolysin determinants from various origins were introduced with and without the sfa genes in such mutants. Table I shows that hemolysin alone exhibits toxic effects after injection of the manipulated strains into the mouse peritoneum or into chicken embryos. The level of toxicity depends on the hly determinant used and is, in general, higher for hly determinants that are of chromosomal origin than for those of extrachromosomal origin. The molecular cause for the difference in toxicity lies in the amount of extracellular hemolysin expressed by the hly determinant (which is mainly a function of sequences located proximal to $h l y C$ ) and in the quality of the secreted hemolysin protein, which may differ in amino acid composition between hemolysins from various hemolytic $E$. coli strains. In addition, the serotype of the bacterial host seems to influence the toxic potential of $E$. coli hemolysins, as demonstrated by

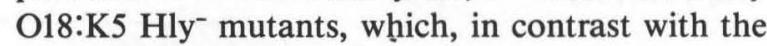
O6:K15 $\mathrm{Hly}^{-}$strains, exhibit only minor changes in toxicity after introduction of the cloned hly genes (table 1).

Two hly determinants, one of chromosomal origin and the other of plasmid origin, were sequenced $[6,11]$, and the amino acid composition for the proteins was deduced from the DNA sequence. All four $h l y$ genes exhibit an unusually high $\mathrm{A}+\mathrm{T}$ content $(\sim 60 \mathrm{~mol} \% \mathrm{~A}+\mathrm{T})$ as compared with other $E$. coli genes (on the average $50 \mathrm{~mol} \% \mathrm{~A}+\mathrm{T}$ ). The codon usage for the Hly proteins also shows unusual deviations from the average $E$. coli codon usage. Both lines of experimental data suggest that the hly genes found today in $E$. coli may not derive from this organism. The secreted hemolysin consists of the unprocessed $h l y A$ product, a protein of 107 kilodalton (kdal).

This protein is found in the supernatant only when the two $h l y$ genes $B$ and $D$ are actively expressed. In the absence of $h l y C$, the HlyA protein is likewise secreted, albeit in lower amounts, but this product is hemolytically inactive. This finding suggests that HlyC protein activates HlyA by a yet unknown mechanism to become hemolytically active, and that HlyB and HlyD function as transport proteins for HlyA. Neither HlyA nor the other $h l y$ gene products that 
Table 1. Virulence tests for Escherichia coli.

Plasmid-located hly genes*

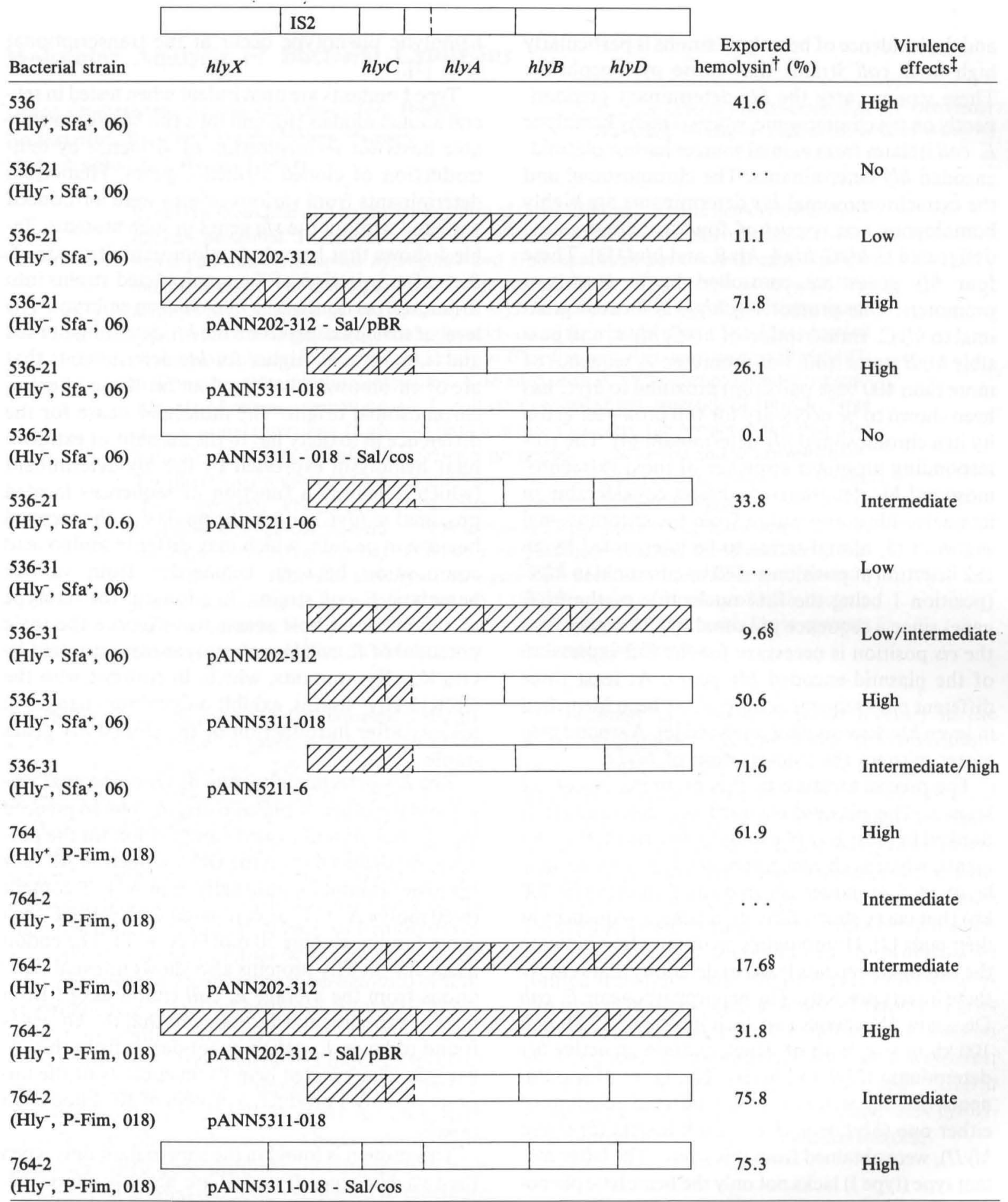

* The hemolysin determinant consists of four genes, $h l y C, A, B$, and $D$. Proximal to $h l y C$ an IS2 element and another sequence, $h l y X$, are located. The recombinant DNAs used parts derived from the plasmid pHly152 (filled boxes) or from the chromosomes of 06 and 018 strains, respectively (open boxes).

$\dagger$ The amount of released hemoglobin is given relative to complete lysis of erythrocytes by absorption at $546 \mathrm{~nm}$ when a constant aliquot of cell-free supernatant is incubated for $30 \mathrm{~min}$ at $37^{\circ} \mathrm{C}$.

$\ddagger$ The virulence effects were estimated in a mouse peritonitis assay (injection of $1 \times 10^{9}-4 \times 10^{7}$ bacteria into the mouse peritonium) and in a chicken embryo model (injection of $1 \times 10^{6}-1 \times 10^{9}$ bacteria into the allantoic cavity of chicken embryos).

$\S$ The amount of exported hemolysin increased by a factor of three to four in the late log phase of growth. 
are required for the transport of hemolysin carry conventional $\mathrm{N}$-terminal transport signal sequences. Yet, there is recent evidence that HlyA carries a sequence for its own transport across the cytoplasmic membrane, since proteins derived from fusions between $h l y A$ and $p h o A$, the latter being devoid of the transport signal (by $\lambda \operatorname{Tn} p h o A[12]$ ), are transported across the cytoplasmic membrane when $<100$ amino acids from the N-terminal end of HlyA are fused to PhoA. However, the transport of these fusion proteins across the outer membrane cannot be accomplished by complementation with $h l y B$ and $h l y D$, a finding which suggests that possible recognition sites on HlyA for HlyB and HlyD are located closer to the
C-terminal end of HlyA, as suggested by previous data [13], or that the transport system (HlyB and HlyD) is recognized only by HlyA in its intact conformation.

Recent data show that extracellular hemolysin is extremely sensitive to lipase treatment (figure 1). Phospholipase $\mathbf{A} 2$ as well as phospholipase $\mathrm{C}$ rapidly inactivate extra- and intracellular hemolysin without affecting the size of the HlyA protein (figure 1). Erythrocytes treated with these lipases are not lysed, nor do they become resistant to hemolysin; this is evidence that association of HlyA with phospholipids may be essential for activity. How and where this association occurs remains unclear.
Figure 1. Sensitivity of extracellular hemolysin (HLY) from Escherichia coli to phospholipase C (PL). Hemolysin was prepared from the supernatant of E. coli $5 \mathrm{~K}$ harboring the recombinant plasmid pANN202-812, which allows the overproduction of hemolysin determined by the plasmid pHly152 (authors' unpublished observations). Treatment of erythrocytes (ERY) with phospholipase $\mathrm{C}$ does not alter the sensitivity to hemolysin (upper curve, ERY + PL). Addition of phospholipase C to erythrocytes and hemolysin leads to a drop in hemolytic activity that is dependent on the concentration of phospholipase (middle curve, ERY + PL + HLY). Treatment of hemolysin with increasing amounts of phospholipase $\mathrm{C}$ inactivates the hemolysin and leads to a drastic reduction of lysis of added erythrocytes (lower curve, HLY + PL + ERY). Incubation with phospholipase was always for $5 \mathrm{~min}$ at $37^{\circ} \mathrm{C}$. The insert shows the electrophoretic mobility on PAGE of the HlyA protein (107 kdal) without treatment (lane $A$ ), after treatment with phospholipase A2 (lane $B$ ), and with phospholipase $\mathrm{C}$ (lane $C$ ). The slower migrating bands in $B$ and $C$ are the respective phospholipases.

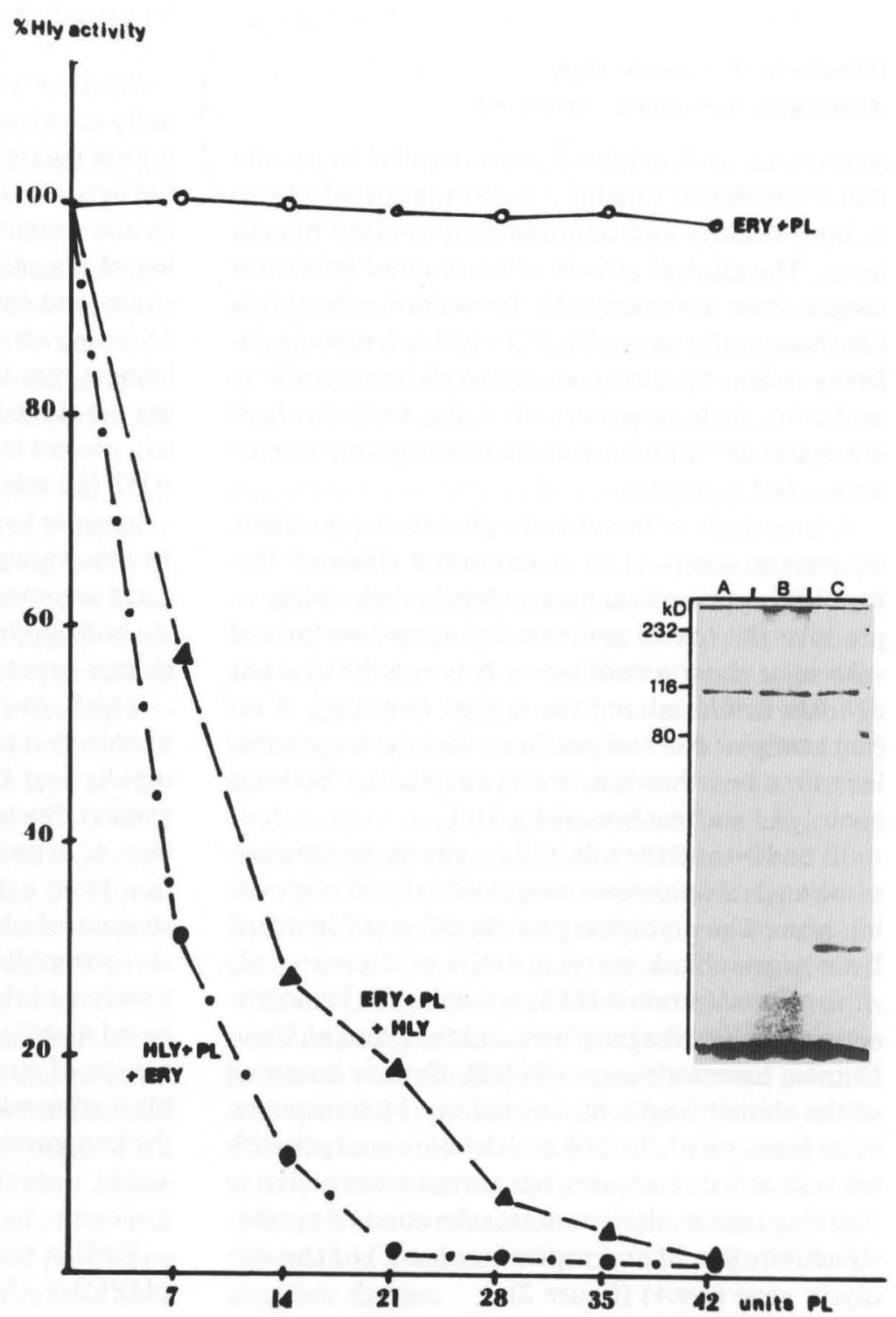




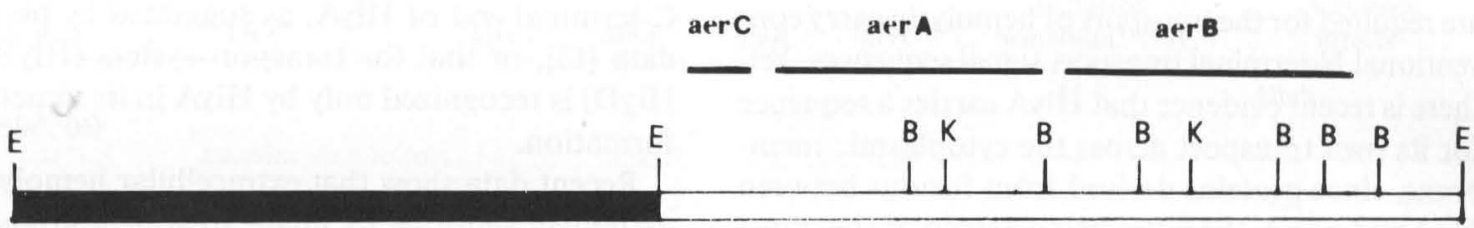

P HPC3 - 1

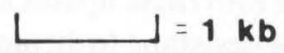

Figure 2. Physical map of the aerolysin-producing plasmid pHPC3-1. Open bars represent cloned Aeromonas hydrophila DNA; closed bars represent the vector ptac11. The region marked A is the structural gene for aerolysin. Regions B and $\mathrm{C}$ denote flanking regions that respectively modulate activity and expression of the aerolysin gene product.

Hemolysin (Cytotoxin) from

Aeromonas hydrophila (Aerolysin)

Aeromonas hydrophila is a gram-negative bacterium that is capable of causing a wide range of infections in both healthy and immunocompromised human hosts. The clinical picture of aeromonal infections ranges from gastroenteritis to rapidly progressing life-threatening wound infections and septicemia. Many strains have been shown to elaborate various exotoxins, including two hemolysins (one of which is a cytotoxic hemolysin termed aerolysin), enterotoxin, and proteases.

A large body of literature implicates the cytotoxic hemolysin, aerolysin, as an important virulence factor. Wild-type isolates vary widely in their ability to produce the toxin, and toxicity assays performed with mice show a correlation between the amount of toxin produced and the rate of mortality. A recent study of 686 isolates from various geographic locations has shown a strong correlation between hemolysis and enterotoxicity [14].

To understand the role of the toxin in Aeromonasassociated infections, we have cloned the corresponding gene. The aerolysin gene (aer $A)$ was identified from a gene bank carrying DNA of a pathogenic A. hydrophila strain $\mathrm{AH} 2$ by screening for hemolytic activity on blood agar plates and for cytotoxicity to Chinese hamster ovary cells [15]. Genetic mapping of the cloned fragment, carried out by transposon mutagenesis with $\operatorname{Tn} 1000$ and deletion analysis with restriction endonucleases, has permitted us to define flanking regions that modulate the onset of synthesis activity (aerB) and expression (aerC) of the aerolysin gene (aerA) (figure 2).
While aerolysin is actively excreted in exponentially growing cultures of $A$. hydrophila $\mathrm{AH} 2$, it is poorly transported in $E$. coli. The cloned aerolysin has been identified as a protein with an apparent molecular weight of $54 \mathrm{kdal}$ in $E$. coli by specific labeling of plasmid-encoded polypeptides in a maxicell strain and by immunoblotting of total lysates of $E$. coli strains harboring aerA plasmids [14]. It is of interest that the protein produced by $E$. coli carrying the cloned aer $A$ ( $54 \mathrm{kdal})$ is larger than the protein present in culture supernatants of $A$. hydrophila AH2 (52 kdal).

In order to characterize the aerolysin gene further and to evaluate the pathogenic potential of aeroly$\sin$ in aeromonal disease, we constructed mutants of A. hydrophila $\mathrm{AH} 2$ that carried deletions in the cloned genes and that failed to produce aerolysin.

The $E$. coli vector pBR322 and its derivatives are unable to replicate stably in $A$. hydrophila and are rapidly lost by segregation (authors' unpublished results). Such vectors can be efficiently introduced into $A$. hydrophila when supplied with a mob function from a plasmid with a broad host range. Our strategy of obtaining aerolysin-negative mutants in A. hydrophila was therefore to introduce deleted derivatives of the aerolysin gene cloned on a pBR322based mobilizable vector into $A$. hydrophila. The detection of mutants required association of a selectable marker with the cloned DNA sequence. We chose the kanamycin-resistance gene from the transposon Tn903 since that gene does not carry sequences homologous to the $A$. hydrophila chromosome.

We first recloned the 5.8-kb EcoRI fragment from pHPC3-1 (figure 2) in the mobilizable vector 
pSUP205, producing the plasmid pHPC3-700. Subsequently, $1.8 \mathrm{~kb}$ of aeromonal DNA sequences between the KpnI sites of pHPC3-700 were replaced by a 1.4-kb KpnI fragment carrying the kanamycinresistance gene of $\mathrm{Tn} 903$. The $1.8 \mathrm{-kb}$ aerA-aerB deletion present on the resulting plasmid pHPC3-702 is a deletion-substitution, since the DNA encoding resistance to kanamycin was inserted at a position formally occupied by the deleted aerA-aerB DNA. $E$. coli recombinants harboring the resulting plasmid pHPC3-702 were completely devoid of both hemolytic and cytotoxic activities.

The marker-exchange procedure of Ruvkun and Ausubel [16] was used to recombine the deletion-kan substitution mutation of pHPC3-702 into a spontaneously derived nalidixic acid-resistant mutant of A. hydrophila AH2 (AB3). Subsequent in vivo recombination and segregation produced genetic recombinants that had the resident aerA-aerB region replaced by the substitution mutation carried by pHPC3-702. One such recombinant was used for subsequent studies.

Southern-blot hybridization was used to confirm the genetic structure of AB3 tox-5 (data not shown). Immunoblots performed with specific antibody directed against aerolysin showed the total absence of aerolysin both in cell lysates and supernatant fluids of AB3 tox-5.

We next determined the $\mathrm{LD}_{50}$ of both the wildtype strain (AB3) and its isogenic aerolysin-negative derivative (AB3 tox-5). Intraperitoneal injection of mice with the parental strain $A B 3$ showed a $L_{50}$ of $\sim 5 \times 10^{7}$ cells, while the aerolysin-negative derivative had an $\mathrm{LD}_{50}$ of $>1 \times 10^{9}$ cells. To exclude the possibility that unlinked mutations affecting toxicity had been introduced during the construction of AB3 tox-5, we reintroduced the wild-type aer determinant on pHPC3-700 into AB3 tox-5. A double cross-over event leading to integration of wild-type aerA-aer $B$ genes was detected by plating on bloodagar plates. Several stable transconjugants were obtained, and one such transconjugant (AB3 tox-5 rev1) was checked for its genetic structure by use of Southern hybridization and for aerolysin production in hemolysin and cytotoxin assays. As shown in table 2, full toxicity was regained with the strain (AB3 tox-5 rev-1), which had a $\mathrm{LD}_{50}$ of $5 \times 10^{7}$ cells. These results clearly demonstrate the association of the toxin with lethality in mice and extend previous results obtained with wild-type isolates producing different amounts of aerolysin [14]. More than $80 \%$
Table 2. Effect of Aeromonas hydrophila AB3, AB3 tox-5, and $\mathrm{AB} 3$ tox-5 rev-1 strains on lethality in mice.

\begin{tabular}{lcc}
\hline Strain & No. of cells injected & $\begin{array}{c}\text { No. of mice dead/ } \\
\text { no. tested }\end{array}$ \\
\hline AB3 & $8 \times 10^{8}$ & $5 / 5$ \\
& $6 \times 10^{8}$ & $9 / 9$ \\
& $4 \times 10^{8}$ & $5 / 5$ \\
& $2 \times 10^{8}$ & $5 / 5$ \\
& $1 \times 10^{8}$ & $3 / 5$ \\
& $5 \times 10^{7}$ & $1 / 5$ \\
AB3 tox-5 & $8 \times 10^{8}$ & $0 / 5$ \\
& $6 \times 10^{8}$ & $1 / 9$ \\
& $4 \times 10^{8}$ & $0 / 5$ \\
& $2 \times 10^{8}$ & $0 / 5$ \\
AB3 tox-5 rev-1 & $1 \times 10^{8}$ & $0 / 5$ \\
& $5 \times 10^{7}$ & $0 / 5$ \\
& $8 \times 10^{8}$ & $5 / 5$ \\
& $6 \times 10^{8}$ & $5 / 5$ \\
& $4 \times 10^{8}$ & $5 / 5$ \\
& $2 \times 10^{8}$ & $5 / 5$ \\
$1 \times 10^{8}$ & $3 / 5$ \\
& $5 \times 10^{7}$ & $2 / 5$ \\
\hline
\end{tabular}

of the mice died within $22 \mathrm{~h}$ after inoculation, and all mice died within $30 \mathrm{~h}$. Moreover, pure cultures of Aeromonas were obtained from the spleens and livers of these mice. The murine model therefore reflects well the rapidly progressing wound infections and septicemia seen with $A$. hydrophila infections in humans.

If aerolysin is important in the pathogenesis of A. hydrophila disease, aerolysin should be produced in vivo, and its production could be indirectly examined by determining whether antibody to aerolysin is produced during aeromonal infections. We therefore obtained serum samples from mice that had survived an $\mathrm{LD}_{50}$ dose. Control serum samples included those from mice injected with an $\mathrm{LD}_{50}$ dose of the aerolysin-negative mutant $\mathrm{AB} 3$ tox-5 and from uninfected mice. The results obtained are shown in figure 3. No antibody to aerolysin was detected in the serum of uninfected mice and of mice infected with the aerolysin-negative mutant. A strong antibody response to aerolysin (and several other polypeptides) was obtained in mice that were infected with the wild-type isolate AB3. The detection of antibodies to aerolysin in the serum of infected mice clearly shows that aerolysin is produced during the infection and is consistent with the hypothesis that the toxin is involved in the pathogenesis of $A$. hydrophila disease. 


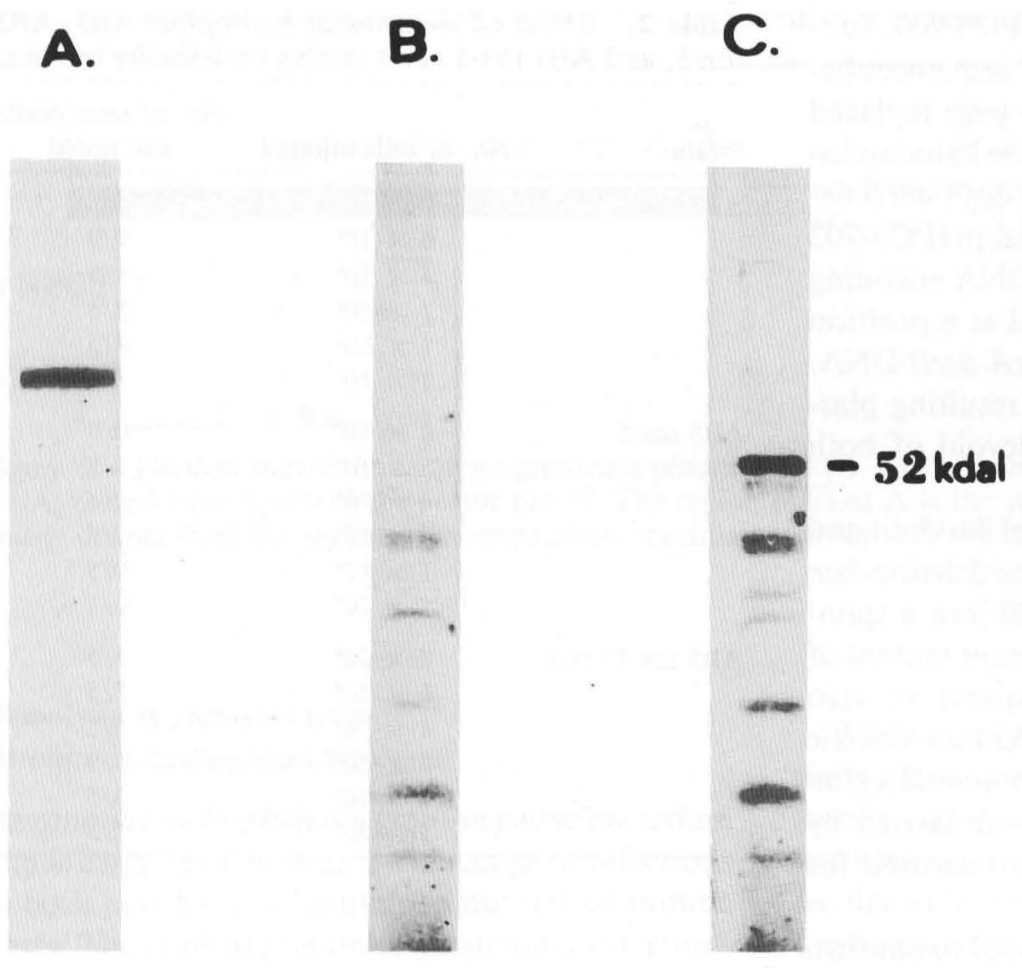

Figure 3. Antisera from $(A)$ uninfected mice, $(B)$ mice injected with strain $\mathrm{AB} 3$ tox-5, and $(C)$ mice injected with AB3 were reacted with supernatant fluids from Aeromonas hydrophila AB3 that had been blotted after SDSPAGE electrophoresis. The large diffuse band in $A$ is methyl green, which has been used to mark the lane. The 52-kdal protein is aerolysin.

\section{Cytolysin (Listeriolysin) from Listeria monocytogenes}

Listeria monocytogenes is a gram-positive, rodshaped bacterium that can cause severe infections in humans and animals. Most strains of L. monocytogenes are producers of a $\beta$-hemolysin, termed listeriolysin. This hemolysin (cytolysin) has been characterized as an extracellular protein that belongs to the group of thiol-activated, cholesterol- inhibited cytolysins and that cross-reacts immunologically with streptolysin O (SLO) [17]. The fact that this hemolytic activity, although often relatively weak in vitro, is possessed by clinical isolates and not or rarely by strains isolated from healthy carriers or from the environment has led to the assumption that hemolysin of $L$. monocytogenes is a virulence factor. Meaningful comparisons between virulent and

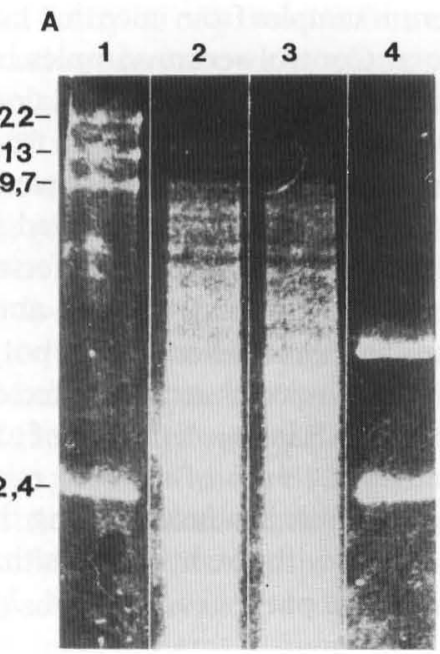

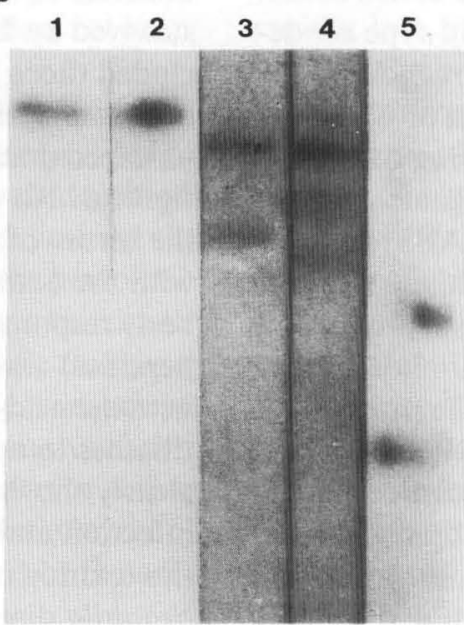

Figure 4. $A$ : Agarose-gel electrophoresis of chromosomal DNA from Listeria monocytogenes digested with EcoRI. Lane 1, BgIII-digested $\lambda$ phage DNA as molecular weight standard; lane 2, $\mathrm{Hly}^{-}$mutant $\mathrm{M} 3$; lane 3, $\mathrm{Hly}^{-}$ mutant M1; lane 4, EcoRI-digested DNA of plasmid pAM170 used as probe. $B$ : Autoradiograph of Southern blots. Lanes 1 and 2, EcoRI-digested DNA of M3 and M1, respectively, hybridized with ${ }^{32}$ P-labeled pAM170 (Southern blot prepared from the gel shown in A); lanes 3 and 4, HindIIIdigested DNA of M3 and M1, respectively, hybridized with ${ }^{32} \mathrm{P}$-labeled pAM170; lane 5, EcoRI-digested pAM170 hybridized with ${ }^{32}$ P-labeled pAM170. 
avirulent strains have so far been hampered by the fact that the genetic backgrounds of such wild-type strains are unclear and probably divergent with respect to several different determinants.

Moreover, there is circumstantial evidence that more than one type of listeriolysin may exist in strains of Listeria. A recent study described by Parrisius et al. [18] has shown that only Listeria ivanovii and two of $26 \mathrm{~L}$. monocytogenes strains of various serogroups secrete a hemolysin that cross-reacts on immunoblots with SLO antibody.

The role of listeriolysin as a virulence factor was demonstrated by inactivating the genetic determinant essential for this protein in $L$. monocytogenes (Mackaness strain serotype $1 / 2 a$ ) by inserting the tetracycline-resistance transposon Tn916 into L. monocytogenes DNA (authors' unpublished observations, and P. Metz, personal communication). The transposon was transferred by means of conjugation of a streptomycin-resistant $L$. monocytogenes recipient strain with Streptococcus faecalis CG110 on membrane filters [19]. Among the tetracycline-resistant transconjugants, mutants that had lost hemolytic activity were detected. Results of hybridization studies with Tn916 DNA as a probe indicate that the transposon is present on a single chromosomal EcoRI fragment and two HindIII fragments in the nonhemolytic transposon mutants (figure 4). This finding suggests that a single transposition event leads to the loss of the hemolytic phenotype, since $\operatorname{Tn} 916$ itself contains one HindIII site but no EcoRI site. Preliminary evidence indicates that the transposition of $\mathrm{Tn} 916$ in these mutants occurs directly in the structural gene for listeriolysin and not in a regulatory site influencing hemolysin synthesis and possibly other virulence properties as well. Analysis of the extracellular proteins from supernatants of wild-type L. monocytogenes $1 / 2 \mathrm{a}$ and of $\mathrm{Tn} 916 \mathrm{Hly}^{-}$mutants indicates the loss of a single major protein of $60 \mathrm{kdal}$, apparently the listeriolysin (figure 5). In one type of
Figure 5. SDS-PAGE of extracellular proteins produced by transposonbearing Listeria monocytogenes. A: Lanes 1 and 3, wild-type strain grown overnight in brain-heart infusion and tryptic soy broth, respectively; lanes 2 and 4, M3 grown overnight in brainheart infusion and tryptic soy broth, respectively. $B$ : $\mathrm{Hly}^{-}$mutant $\mathrm{M} 1$ grown overnight in brain-heart infusion broth. Arrow indicates the position of the presumed truncated listeriolysin.

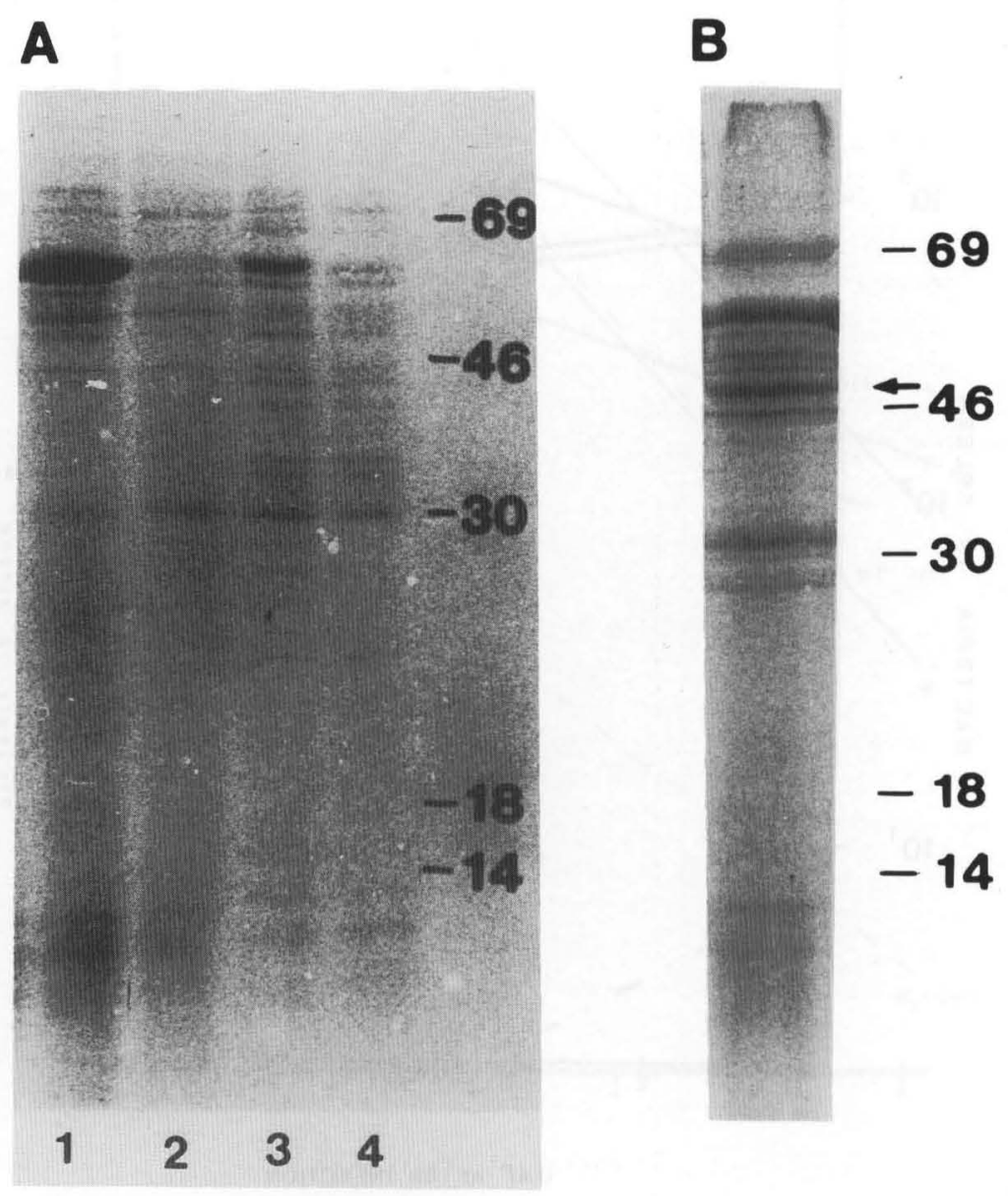


these mutants, a smaller protein of apparent molecular size $49 \mathrm{kdal}$ appears instead of the $60 \mathrm{kdal}$ protein, probably representing a truncated listeriolysin protein (figure 5). The size of the HindIII fragments hybridizing with the Tn916 DNA probe in the two types of nonhemolytic mutants (with and without the truncated protein) suggests that $\mathrm{Tn} 916$ has been in each case inserted in chromosomal sites that were only about $1 \mathrm{~kb}$ apart. This is consistent with the idea that, in the one mutant type, $\operatorname{Tn} 916$ has been inserted in a site close to the $5^{\prime}$ end of the listeriolysin gene, thus generating no, or a very small, truncated listeriolysin protein, whereas in the second mutant type, the insertion occurred in a site $1 \mathrm{~kb}$ more distal, generating the 49-kdal truncated protein.

After iv injection of bacteria of the wild-type (Mackaness strain) into mice, the course of infection previously described by Mackaness [20] for ex- perimental infections of mice with virulent L. monocytogenes was observed. The number of bacteria isolated from the spleens of the animals increased after infection, reached a peak between the third and fourth day after infection, and then declined (figure 6). The number of bacteria isolated from the spleens of the animals 3 days after infection was 50 times higher than that present in the inoculum. Infection by iv injection of the $\mathrm{Tet}^{\mathrm{r}}, \mathrm{Hly}^{+}$ transposon-bearing wild-type strain (wild-type with respect to hemolysin production) resulted in a similar pattern of bacterial multiplication within the animals, although the extent of multiplication was somewhat lower than that observed in the case of the parental Mackaness strain, and a 13-fold increase was observed. Intravenous injection of the $\mathrm{Tet}^{\mathrm{r}}$, Hly' mutant bacteria, however, was not followed by multiplication of the bacteria in the animals; instead,

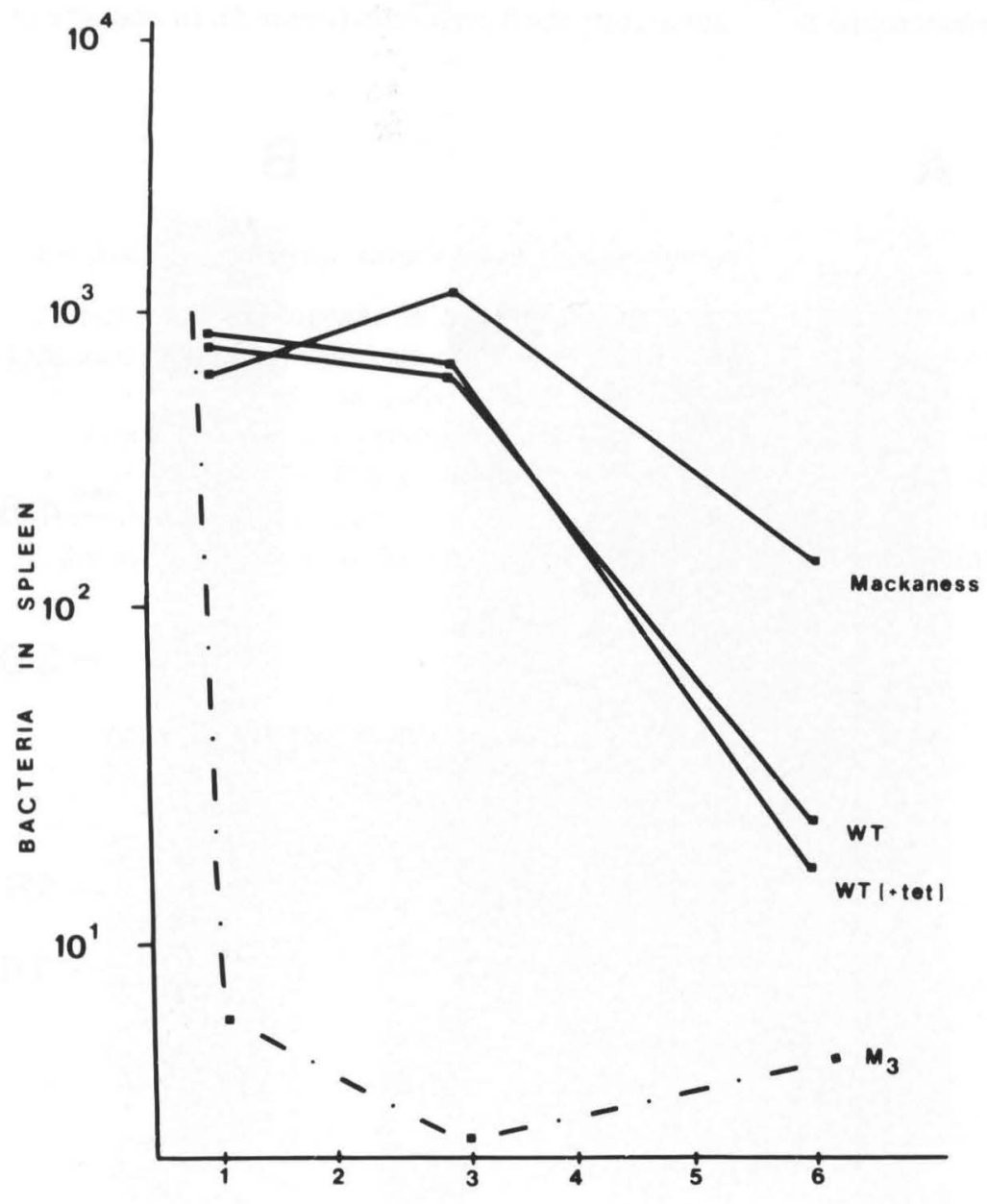

Figure 6. Bacterial counts per spleen 1,3 , and 6 days after intravenously induced infection. Infection dosages were $1.4 \times 10^{3}, 2.7 \times 10^{3}$, and $3.2 \times 10^{3}$ of the Mackaness, wild-type (WT), and M3 strains, respectively. The numbers are means from four or five animals. 
the numbers of bacteria isolated from the spleen declined sharply after their introduction, and, as soon as 1 day after their introduction, the bacteria were virtually eliminated from the animals (figure 6). The few bacteria that could be isolated from the spleens were resistant to tetracycline and were nonhemolytic. Similar results were observed in the experimental infections of mice by other $\mathrm{Hly}^{-}$mutants and randomly selected $\mathrm{Hly}^{+}$transconjugants produced from different crosses.

The infection dose of $\mathrm{Hly}^{-}$bacteria that was used in these experiments $\left(3.1 \times 10^{3}\right.$ bacteria $)$ is unlikely to contain any $\mathrm{Hly}^{+}$revertants, since the average reversion rate in vitro is $10^{-4}$. We expected that if such revertants were generated they would regain their ability to multiply within the animals. Moreover, on the basis of the in vitro data, we expected that most of these revertants would lose resistance to tetracy- cline. To test these expectations, we repeated the experimental infections of mice with the three strains (Mackaness strain; Tet $^{\mathrm{r}}, \mathrm{Hly}^{+}$strain WT; and $\mathrm{Tet}^{\mathrm{r}}$, Hly ${ }^{-}$strain M3), using standard sublethal doses of the hemolytic strains but three orders of magnitude more bacteria of the Hly- mutant $\left(1.3 \times 10^{6}\right)$ (figure 7). The multiplication pattern of the hemolytic strains was similar to that observed earlier. The bacteria isolated from the spleens of the animals infected with WT strain were all $\mathrm{Hly}^{+}$, and similar numbers were isolated on media with or without tetracycline, an observation suggesting that the bacteria maintained their resistance to tetracycline in vivo and that loss of the transposon had not occurred. Most of the bacteria isolated from the animals that had been infected with the Hly- strain M3, however, were hemolytic and sensitive to tetracycline. Such bacteria represented $40 \%, 86 \%$, and $100 \%$ of all those
Figure 7. Bacterial counts per spleen 1,3 , and 6 days after intravenously induced infection. Infection dosages were $2.7 \times 10^{3}, 2.7 \times 10^{3}$, and $1.4 \times 10^{6}$ for the Mackaness, wild-type (WT) and M3 strains, respectively.

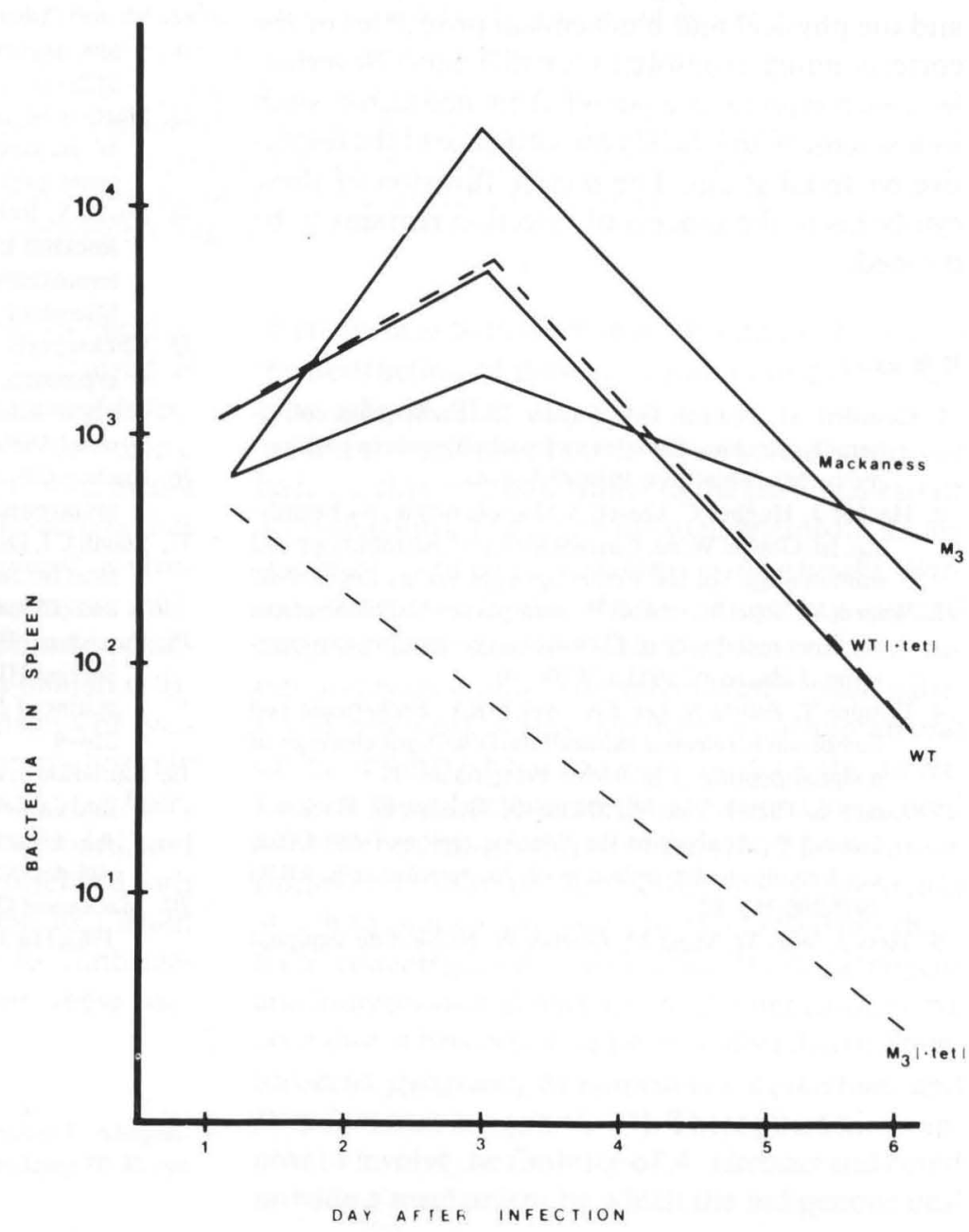


that were isolated 1,3 , and 6 days after infection, respectively. The $\mathrm{Hly}^{+}, \mathrm{Tet}^{\mathrm{s}}$ bacteria were apparently revertants that had lost the transposon and regained the hemolytic phenotype along with the ability to multiply within the animals. Only a small fraction of the bacteria isolated from these animals were still $\mathrm{Hly}^{-}$, a finding which suggests that even when injected in high dosages the $\mathrm{Hly}^{-}$bacteria were unable to multiply within the animals and were rapidly eliminated. These data strongly suggest that the hemoly$\sin$ (listeriolysin) of L. monocytogenes is an essential virulence factor.

\section{Conclusions}

The three virulent bacteria described in this study, $E$. coli, A. hydrophila, and L. monocytogenes, have in common the potential for producing extracellular hemolytic toxins. The complexity of the genetic determinants encoding these hemolysins (cytolysins) and the physical and biochemical properties of the corresponding exoproteins are different. Nevertheless, each represents a potent virulence factor, since its loss reduces drastically the virulence of the respective bacterial strain. The precise function of these cytolysins in the process of infection remains to be defined.

\section{References}

1. Cavalieri SJ, Bohach GA, Snyder IS. Escherichia coli $\alpha-$ hemolysin: characteristics and probable role in pathogenicity. Microbiol Rev 1984;48:326-43

2. Hacker J, Hughes C. Genetics of Escherichia coli hemolysin. In: Goebel W, ed. Current topics of microbiology and immunology. Vol 118. Berlin: Springer Verlag, 1985:139-62

3. Wagner W, Vogel M, Goebel W. Transport of hemolysin across the outer membrane of Escherichia coli requires two functions. J Bacteriol 1983;154:200-10

4. Felmlee T, Pellett S, Lee E-Y, Welch RA. Escherichia coli hemolysin is released extracellularly without cleavage of a signal peptide. J Bacteriol 1985;163:88-93

5. Knapp S, Then I, Wels W, Michel G, Tschäpe H, Hacker J, Goebel W. Analysis of the flanking regions from different hemolysin determinants of Escherichia coli. MGG 1985;200:385-92

6. Hess J, Wels W, Vogel M, Goebel W. Nucleotide sequence of a plasmid-encoded hemolysin determinant and its comparison with a corresponding chromosomal hemolysin sequence. FEMS Letters 1986;34:1-11

7. Knapp S, Hacker J, Jarchau T, Goebel W. Large, unstable inserts in the chromosome affect virulence properties of uropathogenic Escherichia coli O6 strain 536. J Bacteriol 1986;168:22-30

8. Hacker J, Schmidt G, Hughes C, Knapp S, Marget M, Goebel W. Cloning and characterization of genes involved in production of mannose-resistant, neuraminidasesusceptible $(\mathrm{X})$ fimbriae from a uropathogenic O6:K15:H31 Escherichia coli strain. Infect Immun 1985;47:434-40

9. Hughes C, Hacker J, Knapp S, Düvel H, Goebel W. The chromosomal regions encoding haemolysis and fimbriation in a uropathogenic strain of Escherichia coli also promote high levels of serum resistance. Microb Pathogenesis 1987; 2:227-30

10. Hacker J, Hof H, Emödy L, Goebel W. Influence of cloned Escherichia coli hemolysin genes, S-fimbriae and serumresistance on pathogenicity in different animal models. Microb Pathogenesis 1986;1:533-49

11. Felmlee T, Pellett S, Welch RA. Nucleotide sequence of an Escherichia coli chromosomal hemolysin. J Bacteriol 1985;163:94-105

12. Manoil C, Beckwith J. TnphoA: A transposon probe for protein export signals. Proc Natl Acad Sci USA 1985;82: 8129-33

13. Härtlein M, Schiessl S, Wagner W, Rdest U, Kreft J, Goebel W. Transport of hemolysin by Escherichia coli. J Cell Biochem 1983;22:87-97

14. Burke V, Robinson J, Beaman J, Gracey M, Lesmana M, Rockhill R, Echeverria P, Janda JM. Correlation of enterotoxicity with biotype in Aeromonas spp. J Clin Microbiol 1983;18:1196-200

15. Chakraborty T, Huhle B, Bergbauer H, Goebel W. Cloning, expression, and mapping of the Aeromonas hydrophila aerolysin gene determinant in Escherichia coli K-12. J Bacteriol 1986;167:368-74

16. Ruvkun GB, Ausubel FM. A general method for site-directed mutagenesis in prokaryotes. Nature 1981;289:85-8

17. Smyth CJ, Duncan JL. Thiol-activated (oxygen-labile) cytolysins. In: Jelaszewicz J, Wadström T, eds. Bacterial toxins and cell membranes. London: Academic Press, 1978:129-83

18. Parrisius J, Bhakdi S, Roth M, Tranum-Jensen J, Goebel W, Seeliger HPR. Production of listeriolysin by beta-hemolytic strains of Listeria monocytogenes. Infect Immun 1986;51: 314-9

19. Kathariou S, Goebel W. Introduction of the transposon $\operatorname{Tn} 916$ into Listeria spp. In: Courtieu AL, Espaze EP, Reynaud AE. Listeriose-Listeria Listeriosis. Nantes, France: Université des Nantes, 1985-1986:110-5

20. Mackaness GB. Cellular resistance to infection. J Exp Med 1962;116:381-406 